\title{
Symposium
}

\section{Ringing Ears: The Neuroscience of Tinnitus}

\author{
Larry E. Roberts, ${ }^{1}$ Jos J. Eggermont, ${ }^{2,3}$ Donald M. Caspary, ${ }^{4}$ Susan E. Shore, ${ }^{5,6}$ Jennifer R. Melcher, \\ and James A. Kaltenbach ${ }^{8}$ \\ ${ }^{1}$ Department of Psychology, Neuroscience, and Behaviour, McMaster University, Hamilton, Ontario L8S 4K1, Canada, Departments of ${ }^{2}$ Physiology and \\ Pharmacology and ${ }^{3}$ Psychology, University of Calgary, Calgary, Alberta T2N 4N1, Canada, ${ }^{4}$ Department of Pharmacology, Southern Illinois University \\ School of Medicine, Springfield, Illinois 62794-9230, Departments of ${ }^{5}$ Otolaryngology and ${ }^{6}$ Molecular and Integrative Physiology, University of Michigan, \\ Ann Arbor, Michigan 48109-5616, '7Department of Otology and Laryngology, Massachusetts Eye and Ear Infirmary, Harvard Medical School, Boston, \\ Massachusetts 02114-3096, and 'Department of Neurosciences/Head and Neck Institute, The Cleveland Clinic, Cleveland Ohio 44195
}

Tinnitus is a phantom sound (ringing of the ears) that affects quality of life for millions around the world and is associated in most cases with hearing impairment. This symposium will consider evidence that deafferentation of tonotopically organized central auditory structures leads to increased neuron spontaneous firing rates and neural synchrony in the hearing loss region. This region covers the frequency spectrum of tinnitus sounds, which are optimally suppressed following exposure to band-limited noise covering the same frequencies. Cross-modal compensations in subcortical structures may contribute to tinnitus and its modulation by jaw-clenching and eye movements. Yet many older individuals with impaired hearing do not have tinnitus, possibly because age-related changes in inhibitory circuits are better preserved. A brain network involving limbic and other nonauditory regions is active in tinnitus and may be driven when spectrotemporal information conveyed by the damaged ear does not match that predicted by central auditory processing.

\section{Introduction}

While most common after the age of 60 , where $8-20 \%$ of individuals are affected (Coles et al., 1981), chronic tinnitus can occur at any age (Axelsson and Ringdahl, 1989) and is a major servicerelated disability for soldiers returning from Iraq and Afghanistan (Lew et al., 2007). Even when hearing thresholds are in the clinically normal range ( $\leq 20 \mathrm{~dB}$ hearing level), tinnitus sufferers provide evidence for cochlear dead regions (Weisz et al., 2006), outer hair cell damage (Job et al., 2007), or threshold elevations compared with controls (Roberts et al., 2008) that suggest that some degree of hearing impairment is present. Tinnitus is a predictable outcome when the auditory nerve is sectioned by surgery for the removal of acoustic neuromas and is typically not eliminated in preexisting cases (House and Brackmann, 1981; Berliner et al., 1992), implicating changes in central auditory structures as a causal factor. Although threshold shifts experienced by younger individuals after noise exposure often subside, tinnitus is typically associated with these shifts (Emmerich et al., 2002) and may return later in life as age-related changes in brain function unmask a hidden vulnerability (Kujawa and Liberman, 2006). In the United States, $12.5 \%$ of 6 - to 12 -year-olds show a pattern of

\footnotetext{
Received July 28, 2010; revised Sept. 7, 2010; accepted Sept. 8, 2010.

The research was supported by Canadian Institutes of Health Research (CIHR) and Natural Sciences and Engineering Research Council (NSERC) of Canada, the American Tinnitus Association, and the Tinnitus Research Initiative (L.E.R.); CIHR, NSERC, and the Alberta Heritage Foundation for Medical Research (J.J.E.); National Institutes of Health (NIH) Grants DC000151-28 and DC008532-03 (D.M.C.); NIH Grants R01DC004825 and P3005188, the Tinnitus Research Consortium, and Tinnitus Research Initiative (S.E.S.); NIH/NIDCD (National Institute on Deafness and Other Communication Disorders) Grant RC1DC010645, the Tinnitus Research Initiative, Tinnitus Research Consortium, and American Tinnitus Association (J.R.M.); and NIH Grant R01 DC009097 (J.A.K.).

Correspondence should be addressed to Larry E. Roberts, Department of Psychology, Neuroscience, and Behaviour, McMaster University, 1280 Main Street West, Hamilton, 0N L8S 4K1 Canada. E-mail: roberts@mcmaster.ca. DOI:10.1523/JNEUROSCI.4028-10.2010

Copyright $\odot 2010$ the authors $\quad 0270-6474 / 10 / 3014972-08 \$ 15.00 / 0$
}

elevated hearing thresholds in their audiograms typical of noise exposure, suggesting a growing risk associated with recreational sound (Niskar et al., 2001). This observation is sobering in the light of animal research showing that noise exposure at a young age accelerated hearing decline and increased peripheral deafferentation in aged animals compared with unexposed controls (Kujawa and Liberman, 2006).

The most common pattern of hearing loss in the general population (and the most widely studied pattern in the animal literature on tinnitus) consists of elevated thresholds to high-frequency sound. One consequence of high-frequency hearing loss revealed by animal models is that cortical neurons in the hearing loss region begin to respond preferentially to sound frequencies at the edge of normal hearing, such that edge frequencies come to be overrepresented in the cortical tonotopic map (Rajan and Irvine, 1998; Eggermont and Komiya, 2000) (Fig. 1a). This "reorganization" of the tonotopic map, which has been detected in human tinnitus sufferers by neuromagnetic brain imaging (Wienbruch et al., 2006), may occur when neurons that receive diminished thalamocortical input begin to respond to input from their unaffected neighbors via lateral connections on their apical dendrites (Eggermont and Roberts, 2004) (Fig. 1b). Human tinnitus sufferers typically judge sound frequencies covering the hearing loss region to resemble their tinnitus (Noreña et al., 2002), and bandpass noise maskers that produce a postmasking suppression of tinnitus lasting about $30 \mathrm{~s}$ (a phenomenon called "residual inhibition" or RI) do so optimally when the center frequency of the maskers enters the tinnitus frequency range (Roberts et al., 2008) (both phenomena are shown in Fig. 1c). Together, these findings suggest that what neurons do in the hearing loss region causes tinnitus, and stopping what they do suppresses it. What are the neurons doing, and where are they doing it? 
a

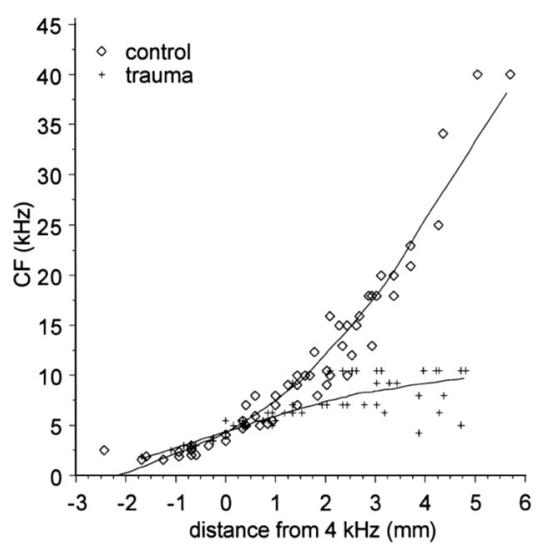

C

b

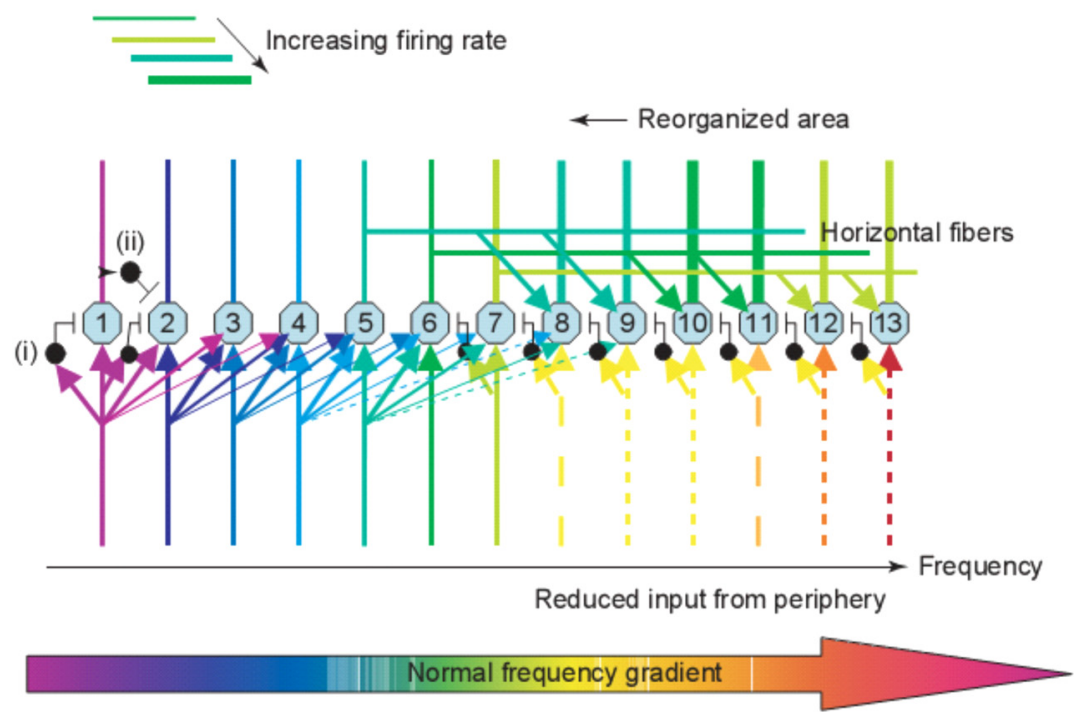

Figure 1. $\boldsymbol{a}-\boldsymbol{c}$, Cortical map reorganization $(\boldsymbol{a}, \boldsymbol{b})$ and psychoacoustic properties ( $\boldsymbol{c}$ ) of tinnitus. $\boldsymbol{a}$, In the normal-hearing cat $(\diamond)$, the characteristic frequency tuning of neurons at low sound intensity shows an orderly gradient from low to high frequencies across the surface of $\mathrm{A} 1$ (tonotopy). In cats exposed to noise trauma $(+$ ), neurons in the hearing loss region (above $\sim 8 \mathrm{kHz}$ in this example) responded preferentially to sound frequencies at the edge of normal hearing (from Eggermont and Komiya, 2000, with permission). $\boldsymbol{b}$, Model for map reorganization in primary auditory cortex. The dashed lines represent diminished thalamocortical input to cortical cells in the hearing loss region. A few inhibitory feedforward connections are indicated (one is labeled i) that suppress the same cells receiving thalamic inputs after one synaptic delay. Feedback inhibition is indicated by one example (ii). Hearing loss reduces excitation and feedforward inhibition arising from thalamocortical pathways, such that the affected neurons begin to respond preferentially to inputs from their unaffected neighbors via horizontal connections in the tonotopic map. The output of the affected neurons remains intact and is heard in terms of their original cochleotopic tuning as the tinnitus percept (from Eggermont and Roberts, 2004, with permission).c, The group-averaged audiogram, tinnitus spectrum, and RI function in 47 participants with chronic bilateral tinnitus. To obtain the tinnitus spectrum, participants rated each of 11 sounds differing in center frequency for similarity to their tinnitus (a likeness rating $>40$ indicated a sound beginning to resemble tinnitus). The RI function shows the suppression of tinnitus reported after cessation of band-limited noise sounds differing in center frequency ( -5 equaled "tinnitus gone;" 0 , no change; +5 , tinnitus worse). The Rl function is plotted negative up to show its similarity to the tinnitus spectrum. WN, white noise (from Roberts et al., 2008, with permission).

\section{Distributed activity in auditory pathways}

Damage to the cochlea induced by traumatizing sound, ototoxic agents, or other means increases the spontaneous firing rate (SFR) of neurons in several auditory structures including the dorsal cochlear nucleus (DCN) and ventral cochlear nucleus (VCN) (Kaltenbach, 2006; Bledsoe et al., 2009), the central nucleus of the inferior colliculus (IC) (Ma et al., 2006; Mulders and Robertson, 2009), and the secondary (A2) (Eggermont and Kenmochi, 1998) and primary (A1) (Noreña and Eggermont, 2003) auditory cortices, but not necessarily in auditory nerve fibers (Eggermont and Roberts, 2004). In the DCN, SFR increases across the cochleotopic representation, peaking $\sim 1$ octave above the frequency of the traumatizing sound (Kaltenbach et al., 2002). This frequency profile is similar to tinnitus measured in noise-exposed animals (Kaltenbach et al., 2004), where suppression of behavioral responses conditioned to silence among a background of several frequencies reveals the presence of tinnitus in this frequency range. Enhanced SFR in the DCN is observed principally in fusiform cells (Brozoski et al., 2002; Finlayson and Kaltenbach, 2009) and persists following lesioning of the cochlea (Zacharek et al., 2002), demonstrating its independence of peripheral mechanisms. However, because behavioral evidence of tinnitus is not eliminated by ablation of the DCN (Brozoski and Bauer, 2005), chronic tinnitus appears to be dependent on changes taking place at more than one level of the auditory system. Increased SFRs in fusiform cells in the DCN and pyramidal cells in the auditory cortex may reflect a shift in the balance of excitation and inhibition in cortical networks as powerful inhibitory regulation is diminished by deafferentation of central auditory structures. In DCN, increased SFRs have been observed to develop over several days (Kaltenbach, 2006), suggesting that compensatory homeostatic plasticity (Turrigiano and Nelson, 2004; Schaette and Kempter, 2006) may also be occurring in this structure or at higher auditory levels that feed back to subcortical nuclei over corticofugal pathways. Compared with these findings implicating increased SFRs in tinnitus, changes in burst firing have been less extensively studied. In DCN, burst firing increased following noise exposure, accounting for $\sim 50 \%$ of SRF increases seen in this structure (Finlayson and Kaltenbach, 2009). However, in AC, burst firing increased after noise exposure but returned to baseline levels within a few hours (Noreña and Eggermont, 2003), while SFRs did not return to baseline over the time intervals that were studied in the AC (Noreña and Eggermont, 2003) or in the DCN (Kaltenbach et al., 2005). These results suggest that although a role for burst firing cannot be discounted, increased SFRs appear more likely to underlie persisting noise-induced tinnitus than is burst firing in cortical and subcortical neurons.

One can question, however, whether unstructured spontaneous activity is sufficient to produce a coherent percept (Singer, 1999), including the percept of phantom sound. Whereas at the level of spontaneous firings in the auditory nerve there is no evidence of burst firing (serial synchrony) or correlated firing between nerve fibers (spatial synchrony), such evidence is clearly present in the central auditory system (DCN and subdivisions of the auditory cortex) (Eggermont, 2000; Finlayson and Kaltenbach, 2009) (H. O’Donahue, L. Campagnola, and P. B. Maris, unpub- 
lished observations). In normal-hearing cats, correlated firing between neuron pairs covering two cortical areas (anterior and posterior auditory fields) had on average a cross-correlation coefficient $R \approx 0.01$ during baseline, whereas during stimulation it was $\approx 0.03$. Within a cortical area, $R$ was 10 times larger $(\approx 0.1)$, decreased slowly with distance on the cortical surface, and was only modestly increased by presenting sound. Decisions of the presence or absence of a stimulus based either on multiunit firing rate or $R$ indicated that while optimal criteria resulted in the same number of false positives, a decision based on $R$ had a much smaller number of false negatives (Eggermont, 2000). Hence using synchronized firings resulted in better prediction. Synchronization between areas or within distant points in the same cortical area may thus be more important than local correlation for the percept of sound. Two hours after noise trauma, SFR was increased twofold and $R$ was further increased (Noreña and Eggermont, 2003). Three hours after the trauma SFR was significantly larger than in controls at all recording sites tested and not in the region of the hearing loss alone, although that region showed more pronounced changes. Peak cross-correlation coefficients were also significantly increased by $\sim 50 \%$, but most notably, specifically in the hearing loss region relative to other regions (Seki and Eggermont, 2003). The latter result suggests that increased neural synchrony in the deafferented hearing loss area, forged by spike timing-dependent plasticity (Eggermont, 2007) in this region, underlies the spectrum of tinnitus which covers the same frequency region in human tinnitus sufferers. Like tinnitus spectra, RI functions relating tinnitus suppression in humans to the center frequency (CF) of bandpass noise maskers also show optimal tinnitus suppression when the CF of the maskers enters the hearing loss region (Fig. 1c). RI may be generated when suprathreshold bandpass noises presented to this region inject feedforward inhibition disrupting synchronous activity occurring there, or when the maskers rescale neuron input-output functions in subcortical structures (Dean et al., 2005), reducing SFRs in these regions and their driving force in auditory pathways.

Will the neurons generating tinnitus cease their activity if disrupted by maskers for longer periods of time? Although the results for tinnitus sufferers are variable, on average RI duration increases as a function of the logarithm of masker duration, lengthening to $\sim 100 \mathrm{~s}$ for maskers of $100 \mathrm{~s}$ duration but only to $\sim 200$ s for maskers 10 times longer, with little gain thereafter for most (but not all) individuals with tinnitus (Terry et al., 1983; Vernon and Meikle, 2003). Repeated daily inductions of RI over 3 months had no effect on psychoacoustic measurements of tinnitus loudness or spectra (Roberts et al., 2008). In cats with noiseinduced hearing loss, 3 weeks of recovery in quiet resulted in changes of the cortical tonotopic map in AI that were accompanied by increased SFR and increased neural synchrony in the reorganized areas (Noreña and Eggermont, 2005, 2006). However, if, instead, recovery was in an enhanced acoustic environment (EAE), with frequency content and level such that it balanced the activity of auditory nerve fibers across the cat's full frequency range, the reorganized tonotopic map typical of noiseexposed cats (Fig. 1a) could be prevented, and both SFR and $R$ were within normal limits (Noreña and Eggermont, 2005, 2006). This was interpreted as evidence that the biological substrates of tinnitus were now absent and tinnitus was likely prevented as well. Sound therapies based on this study have yielded inconclusive results in humans (Moffat et al., 2009). In contrast, hyperacusis (abnormal intolerance of moderate to high-intensity sounds, often accompanied by hearing loss and tinnitus) can be corrected by exposure $3 \mathrm{~h}$ daily for 15 weeks to background sounds disproportion- ately weighting the frequency range of threshold elevation (Noreña and Chery-Croze, 2007). Rescaling of neuron input-output functions by background sound may be responsible for this effect, but its effects on tinnitus (which could depend on consequent mechanisms) have not been systematically studied.

Of the three types of neural activity discussed here as correlates of tinnitus (increases in SFRs, neural synchrony, and bursting activity), changes in neural synchrony measured in animal models of hearing loss (Seki and Eggermont, 2003) appear to correspond most closely to the frequency profile of tinnitus and hearing loss measured in human tinnitus patients (Noreña et al., 2002; Roberts et al., 2008). Elevated SFRs may play a crucial role by providing a substrate for increased synchronous activity, but synchrony may be the more prominent neural correlate of tinnitus because it may be more likely than spontaneous activity to impact postsynaptic targets and recruit cortical and downstream neurons into a tinnitus percept. A role for synchronous activity is further implicated by a report that oscillatory brain activity generated in the left and right auditory cortices and measured by magnetoencephalography (MEG) is larger in tinnitus patients than in controls and tracks the laterality of the tinnitus percept (Weisz et al., 2007). While these observations suggest insights into the neural basis of tinnitus, several key questions nevertheless remain unanswered. Several studies have revealed elevated SFRs in subcortical structures following hearing loss caused by noise trauma, but synchronous neural activity in these structures and its relation to behavioral evidence of tinnitus have not been extensively investigated. Little is known about the extent to which output from the AC contributes to neural changes in subcortical nuclei, or about whether changes induced by homeostatic plasticity in one auditory structure affect or compensate for changes in other levels of the projection pathway as might be expected. Increases in SFRs develop at different rates in different auditory structures (for example, more rapidly in the AC and VCN than in the DCN) (Kaltenbach, 2006; Bledsoe et al., 2009) and may reflect mechanisms that change with time, since elevations in the DCN survive cochlear ablation (Zacharek et al., 2002), but those in the IC apparently do not (Mulders and Robertson, 2009). Also debated is whether contrast enhancement caused by discontinuities in the balance of excitation and inhibition across the edge of normal hearing contributes to tinnitus, in addition to contributions arising from abnormal neural activity in tonotopic regions affected by hearing loss (Kiang et al., 1969; Llinás et al., 2005; König et al., 2006). Important questions remain about how specific patterns of peripheral damage to inner and outer hair cells and to stereocilia affect neural changes in central auditory structures and how these patterns relate to the development of tinnitus. Physiological (Kaltenbach et al., 2002), otoacoustic (Job et al., 2007), and computational (Schaette and Kempter, 2006) evidence suggests that damage to outer hair cells may be predisposing, but the findings are not consistent (Bauer et al., 2007). It is also well known that hearing loss and tinnitus are more common in older individuals, but that tinnitus is not an inevitable correlate of hearing loss and aging. While different patterns of cochlear pathology might account for tinnitus with and without hearing loss in older individuals, the relationships among aging, hearing loss, and tinnitus need to be better understood.

\section{Tinnitus, age, and inhibition}

Although it can occur at any age, chronic tinnitus is more common in the senior years when hearing is often impaired for sound frequencies $>2-4 \mathrm{kHz}$, which is the region where tinnitus commences (Fig. 1c). However, many older individuals show elevated 
hearing thresholds in this frequency range but do not report tinnitus (Roberts et al., 2008). If tinnitus reflects a shift in the balance of excitation and inhibition in central auditory structures, one answer to this puzzle may lie in understanding how cortical and subcortical inhibitory circuits change with aging and the mechanisms involved.

Partial deafferentation of the central auditory system due to aging, noise trauma, or other peripheral insults may produce plastic maladaptive compensatory changes resulting in net downregulation of functional inhibition (Syka, 2002; Dong et al., 2010; Eggermont, 2010). Age-related downregulation of inhibition has been reported throughout the auditory neuraxis (Caspary et al., 2008; Frisina, 2010). Noise exposure studies suggest that insults to the auditory system in childhood or as a young adult may result in substantial/partial afferent nerve degeneration not detectable by simple threshold measures. These changes may occur in the absence of temporary or only modest permanent elevation of auditory thresholds with little obvious hair cell damage (Bauer et al., 2008; Kujawa and Liberman, 2009). Progressive age-related loss of central inhibition could unmask areas of increased spontaneous activity, neural synchrony, and/or hyperactivity made vulnerable by earlier peripheral insults, leading to the generation of a tinnitus percept later in life.

Current research is focused on understanding the inhibitory changes that occur with aging and how they relate to those associated with tinnitus induced by noise exposure in animal models. DCN fusiform cells, which appear to form an important link in the tinnitus pathway, show age-related changes in glycineinhibitory neurotransmission (Brozoski et al., 2002; Caspary et al., 2005) that are expressed in the altered subunit makeup of pentomeric heteromeric strychnine-sensitive glycine receptors (GlyRs) and in the anchoring/trafficking protein, gephyrin (Wang et al., 2009a). GlyR changes are also induced in these markers by noise exposure (Wang et al., 2009b). (1) In young rats with evidence of tinnitus induced by noise exposure, GlyR $\alpha_{1}$ protein decreased in middle- and high-frequency regions of the DCN while gephyrin levels increased, suggesting changes in intracellular receptor trafficking months after traumatic sound. Consistent with decreased $\alpha_{1}$ subunit protein levels, strychnine binding studies showed significant tinnitus-related decreases in the number of GlyR-binding sites, supporting a tinnitus-related change in the number and/or composition of GlyRs (Wang et al., 2009b). (2) Aging also decreases GlyR $\alpha_{1}$ protein in middle- and high-frequency regions of the DCN, and there are age-related losses of GlyR binding as well. In aged rat DCN, noise trauma increased $\alpha_{1}$ protein in the middle- and high-frequency region with a commensurate increase in GlyR receptor binding, while aging and noise trauma increased gephyrin protein levels, suggesting altered trafficking and anchoring functions in response to decreased acoustic nerve activity. Deafferentation and agerelated changes in markers of GABA inhibition in the IC have been reviewed by Syka (2002) and Caspary et al. (2008).

Biochemical and physiologic markers of inhibitory neurotransmission in A1 are also altered by noise trauma and physical damage to the periphery (Popelár et al., 1987; Syka et al., 1994). Vertical and horizontal inhibitory GABAergic microcircuits are found throughout AI layers (Prieto et al., 1994a,b), and because (depending on the species) $20-40 \%$ of neurons in these circuits release GABA, any changes in GABAergic neurotransmission would likely have a profound effect on the response properties of auditory neurons (for examples, see Foeller et al., 2001; Wang et al., 2002). Aging is accompanied by reduced A1 message and protein levels of the GABA-synthetic enzyme GAD across layers of A1, with GAD protein losses between 40 and 60\% (Ling et al., 2005). Functionally, aging alters frequency-receptive fields in rodent A1 (Willott et al., 1993; Turner et al., 2005) with age-related changes detected in the shape and reproducibility of receptive fields, an increased ability to be driven by extracellular current (Turner et al., 2005), and increased spontaneous and driven activity across all A1 layers, with the greatest increases in layers II-IV (Hughes et al., 2010). These effects of aging on inhibitory processes could unmask or sum with subclinical tinnitus-related changes, causing an activity-dependent downregulation of inhibitory function and increasing the possibility that pathological activity in central auditory pathways is perceived as phantom sound.

\section{Role of the somatosensory system in the generation and modulation of tinnitus}

The observation that approximately two-thirds of people with tinnitus are able to alter the loudness and pitch of their tinnitus via somatic maneuvers, such as jaw clenching or tensing their neck muscles (Pinchoff et al., 1998; Levine, 1999), has led to the search for neural connections between the auditory and somatosensory systems that could explain these phenomena (Shore, 2005; Shore et al., 2007; Dehmel et al., 2008). Indications that tinnitus can arise from somatosensory insults make determination of these connections all the more important (Rubinstein et al., 1990; Levine, 1999). Anatomical tract-tracing (Shore et al., 2007) and physiological studies (Kanold and Young, 2001; Shore, 2005) demonstrate auditory connections with the dorsal column and trigeminal systems at the very lowest levels of each sensory system where cells in the dorsal root and trigeminal ganglia send axons to terminate in the cochlear nucleus $(\mathrm{CN})$. These projections, as well as those from the brainstem somatosensory nuclei (cuneate, gracilis, and spinal trigeminal), terminate as mossy fibers and en-passant endings primarily in the granule cell domain of the $\mathrm{CN}$ that surrounds the VCN and extends into the second layer of the DCN (Shore et al., 2007). En-passant endings are also found in magnocellular regions of the VCN and deep DCN. Both types of endings colabel with vesicular glutamate transporter 2 (VGLUT2), thus classifying them as glutamatergic. Interestingly, VIIIth nerve fibers conveying auditory information that terminate in the CN label exclusively with VGLUT1 and not VGLUT2, enabling study of the fates of the auditory and nonauditory endings after cochlear damage (see below).

Stimulating the trigeminal ganglion in the absence of sound produces primarily excitation of VCN neurons (Shore et al., 2003) and both excitation and inhibition in DCN neurons, with inhibition presumably arising from cartwheel cells (Davis et al., 1996; Shore, 2005). The locations and response patterns of units responding to trigeminal stimulation are consistent with those of fusiform or giant cells (Hackney et al., 1990) in the DCN, and bushy or stellate cells in the VCN (Shore et al., 2003). Importantly, these studies show that preceding an acoustic stimulus by trigeminal stimulation can modulate both the firing rates and temporal response patterns to the sound (Shore, 2005; S. Koehler, P. B. Manis, S. Pradhan, and S. Shore, unpublished observation). This bimodal integration is replicated in neurons of the IC (Jain and Shore, 2006), which receive converging inputs from both the DCN and somatosensory nuclei (Zhou and Shore, 2006). Somatosensory stimulation can affect both sound-driven and spontaneous rates for long periods of time (up to an hour) following cessation of the stimulation, a phenomenon that may be due to long-term potentiation or depression (Tzounopoulos et al., 2007). Preceding an acoustic stimulus by electrical stimulation of somato- 
sensory pathways can alter spike timing of the sound-evoked response and the synchrony of firing between neurons in the DCN (S. Koehler, P. B. Manis, S. Pradham, S. Shore, unpublished observations), an additional proposed correlate of tinnitus (Eggermont, 2005).

Increased SFRs in DCN principal cells have been observed following noise-induced cochlear damage and have been proposed as correlates of tinnitus in animal behavioral models (Bauer et al., 2000; Brozoski et al., 2002; Rachel et al., 2002; Kaltenbach et al., 2004). One mechanism for the increased SFR could be a reduction in inhibitory inputs to the fusiform cells (Salvi et al., 2000), or changes in glycine receptors (see above) unmasking the excitability of the fusiform cells (Caspary et al., 1987; Wang et al., 2009b). Another mechanism, however, could be an increase in excitatory inputs to the $\mathrm{CN}$ from the somatosensory system after noise damage (Zeng et al., 2009). One and 2 weeks after unilateral cochlear ablation, the number of VGLUT2 + terminals increases in those regions that receive somatosensory inputs, while VGLUT1+ terminals decrease, signifying an enhanced somatosensory influence on the $\mathrm{CN}$ after decreased auditory nerve innervation of the $\mathrm{CN}$ (Zeng et al., 2009). This altered balance of inputs from auditory and somatosensory structures affects bimodal integration, imparting greater strength to the somatosensory inputs. One physiological consequence of the increased number of VGLUT2+ inputs is that DCN neurons become more responsive to somatosensory stimulation following cochlear damage (Shore et al., 2008), with decreases in latencies and thresholds to somatosensory stimulation and enhanced bimodal integration.

The upregulation of glutamatergic somatosensory innervation of both granule and magnocellular cells in the $\mathrm{CN}$ shown by Zeng et al. (2009) could account for the increase in SFR in DCN fusiform cells after cochlear damage. Indeed, when analyzed in terms of their responsiveness to somatosensory stimulation, the SFR increases observed following cochlear damage were confined to those DCN fusiform cells that showed excitatory responses to trigeminal stimulation: neurons that showed inhibitory or no responses to trigeminal stimulation did not have raised SFRs following noise trauma (Shore et al., 2008). One consequence of increased SFR in specified groups of neurons is increased synchrony of firing between neurons (Seki and Eggermont, 2003), which has also been reported in the rat DCN after noise damage (H. O'Donahue, L. Campagnola, and P. B. Manis, unpublished observations). Synchrony in one region can be transmitted with high fidelity to other brain centers (Masuda and Kori, 2007; Takahashi et al., 2009), and may be one mechanism by which the cortical synchrony reported above occurs.

\section{Imaging of brain network activity in tinnitus}

While the majority of individuals with tinnitus report a tonal sensation or ringing or noise-like sounds with a wider bandwidth, the percept can include more complex sounds (e.g., crickets, buzzing, pulsing noise), fluctuate over time, and be perceived in one or both ears or be heard diffusely in the head. This variability may reflect distinct patterns of injury and forms of tinnitus (Levine, 2006) that are shaped by neural plasticity operating in auditory pathways. Associated symptoms of anxiety, diminished concentration, disrupted sleep, and depression are present in many clinical patients and may also express in functional brain imaging data. However, because in all cases a sound is perceived, there should be enough commonality of mechanism across tinnitus patients to show consistent physiological results.

Consistent with this hypothesis, positron emission tomography (PET) studies have reported elevated blood flow in several auditory structures in individuals experiencing tinnitus compared with control conditions (for review, see Lanting et al., 2009). Enhanced activity has been observed in the medial geniculate nucleus, the primary and secondary auditory cortex, the auditory brainstem, and temporal-parietal association areas (Lockwood et al., 1998; Giraud et al., 1999; Plewnia et al., 2007). Magnetic resonance imaging has revealed differences in soundevoked blood oxygenation level-dependent(BOLD) responses between tinnitus and non-tinnitus groups in cortical ( $\mathrm{Gu}$ et al., 2008) and subcortical auditory nuclei (Melcher et al., 2009) and found evidence for structural differences in the thalamus (Mühlau et al., 2006), the auditory brainstem (Landgrebe et al., 2009), and the auditory cortex (Schneider et al., 2009). Enhanced BOLD responses evoked by sound stimuli may also reflect abnormal loudness growth (hyperacusis) in individuals with tinnitus (Melcher et al., 2009). When this factor is taken into account, elevated sound-evoked responses in subcortical auditory nuclei appear to reflect hyperacusis, whereas in the auditory cortex, augmented BOLD responses may be associated with both hyperacusis and tinnitus (Gu et al., 2010). Elevated cortical activation may reflect attention drawn to the auditory domain by the presence of tinnitus, while subcortical nuclei may be less affected by attentional state.

Brain changes in tinnitus are not, however, restricted to auditory regions. Increased functional responses have been reported in several nonauditory structures including the hippocampus (Lockwood et al., 1998), amygdala (Mirz et al., 2000), and cingulate gyrus (Mirz et al., 2000; Plewnia et al., 2007), while gray matter decreases have been reported in the hippocampus (Landgrebe et al., 2009) and the subcallosal area including the nucleus accumbens (Mühlau et al., 2006). Phase coupling of MEG activity between the anterior cingulum and right frontal lobe activity was stronger in tinnitus than in control subjects and correlated with individual tinnitus distress ratings (Schlee et al., 2008). These results suggest network behavior in tinnitus that engages the thalamus and may be a prerequisite for the conscious perception of sound (Schlee et al., 2008). Limbic and prefrontal areas are associated with emotion and attention and may contribute to distress behavior, which is present in many individuals with tinnitus (Jastreboff et al., 1996). Alternatively, nonauditory regions may play a more direct role in the generation of the tinnitus percept. One recent account attributes chronic tinnitus to the failure of a noise cancellation system mediated by subcallosal structures that in the undamaged brain is responsible for preventing the perception of unwanted sounds (Rauschecker et al., 2010). While current studies do not converge on a consensus regarding the role of nonauditory centers in tinnitus, the results are consistent with the growing view that multiple brain areas controlling executive functions are linked to one another through temporally coordinated activity (Buckner et al., 2009) and, in the case of tinnitus, may be important for the perception of phantom sound.

\section{Tinnitus may reveal a mechanism of normal auditory perception}

Tinnitus can be described as the conscious perception of a sound that is not generated by any source outside the body. Phantom sound could be generated by abnormal spontaneous activity in the auditory system or by malfunction of a mechanism that normally prevents such activity to be audible, or both factors. Suggestions for interacting mechanisms sensitive to always-present background sound comes from studies that kept normal-hearing people in a soundproof room for 5-10 min (Del Bo et al., 2008). 
Nearly all of them described hearing sound and using qualitative descriptions that resemble those of people describing their tinnitus. Paraphrasing Aristotle, the brain may "abhor silence" and resort either to a short-term synaptic gain increase along the auditory pathway or to a release from inhibition in the absence of auditory input.

The function of the auditory system is to represent and communicate to other brain regions information about sounds that are present in the environment. A feature of the model described in Figure $1 b$ for the auditory cortex in tinnitus is that while thalamocortical input is diminished in the region of impaired hearing, the output of the affected neurons remains intact. A reasonable extrapolation suggests that information is communicated from the reorganized region implying the presence of (tinnitus-like) sounds in the environment that is not congruent with bottom-up, spectrotemporally specific input from auditory pathways. The mismatch of top-down (predictive) and bottom-up (obtained) information in auditory cortical or subcortical structures may call auditory attention and induce brain network activity as the brain attempts to build a more accurate representation of the auditory scene.

\section{References}

Axelsson A, Ringdahl A (1989) Tinnitus-a study of its prevalence and characteristics. Br J Audiol 23:53-62.

Bauer CA, Brozoski TJ, Holder TM, Caspary DM (2000) Effects of chronic salicylate on GABAergic activity in rat inferior colliculus. Hear Res 147:175-182.

Bauer CA, Brozoski TJ, Myers K (2007) Primary afferent dendrite degeneration as a cause of tinnitus. J Neurosci Res 85:1489-1498.

Bauer CA, Turner JG, Caspary DM, Myers KS, Brozoski TJ (2008) Tinnitus and inferior colliculus activity in chinchillas related to three distinct patterns of cochlear trauma. J Neurosci Res 86:2564-2578.

Berliner KI, Shelton C, Hitselberger WE, Luxford WM (1992) Acoustic tumors: effect of surgical removal on tinnitus. Am J Otol 13:13-17.

Bledsoe SC Jr, Koehler S, Tucci DL, Zhou J, Le Prell C, Shore SE (2009) Ventral cochlear nucleus responses to contralateral sound are mediated by commissural and olivocochlear pathways. J Neurophysiol 102:886-900.

Brozoski TJ, Bauer CA (2005) The effect of dorsal cochlear nucleus ablation on tinnitus in rats. Hear Res 206:227-236.

Brozoski TJ, Bauer CA, Caspary DM (2002) Elevated fusiform cell activity in the dorsal cochlear nucleus of chinchillas with psychophysical evidence of tinnitus. J Neurosci 22:2383-2390.

Buckner RL, Sepulcre J, Talukdar T, Krienen FM, Liu H, Hedden T, AndrewsHanna JR, Sperling RA, Johnson KA (2009) Cortical hubs revealed by intrinsic functional connectivity: mapping, assessment of stability and relation to Alzheimer's disease. J Neurosci 29:1860-1873.

Caspary DM, Pazara KE, Kössl M, Faingold CL (1987) Strychnine alters the fusiform cell output from the dorsal cochlear nucleus. PG-273-82. Brain Res 417(2):273-282.

Caspary DM, Schatteman TA, Hughes LF (2005) Age-related loss of response inhibition in rat dorsal cochlear nucleus. J Neurosci 25:10952-10959.

Caspary DM, Ling L, Turner JG, Hughes LF (2008) Inhibitory neurotransmission, plasticity and aging in the mammalian central auditory system. J Exp Biol 211:1781-1791.

Coles RRA, Davis AC, Haggard MP (1981) Epidemiology of tinnitus. In: Ciba Foundation symposium 85, Tinnitus (Evered D, Lawrenson G, eds), pp 16-25. London: Pitman.

Davis KA, Miller RL, Young ED (1996) Effects of somatosensory and parallel-fiber stimulation on neurons in dorsal cochlear nucleus. J Neurophysiol 76:3012-3024.

Dean I, Harper NS, McAlpine D (2005) Neural population coding of sound level adapts to stimulus statistics. Nat Neurosci 8:1684-1689.

Dehmel S, Cui YL, Shore SE (2008) Cross-modal Interactions of auditory and somatic inputs in the brainstem and midbrain and their imbalance in tinnitus and deafness. Am J Audiol 17:S193-S209.

Del Bo L, Forti S, Ambrosetti U, Costanzo S, Mauro D, Ugazio G, Langguth B,
Mancuso A (2008) Tinnitus aurium in persons with normal hearing: 55 years later. Otolaryngol Head Neck Surg 139:391-394.

Dong S, Mulders WH, Rodger J, Woo S, Robertson D (2010) Acoustic trauma evokes hyperactivity and changes in gene expression in guinea-pig auditory brainstem. Eur J Neurosci 31:1616-1628.

Eggermont JJ (2000) Sound induced correlation of neural activity between and within three auditory cortical areas. J Neurophysiol 83:2708-2722.

Eggermont JJ (2005) Tinnitus: neurobiological substrates. Drug Discov Today 10:1283-1290.

Eggermont JJ (2007) Correlated neural activity as the driving force for functional changes in auditory cortex. Hear Res 229:69-80.

Eggermont JJ (2010) Tinnitus. In: Oxford handbook of auditory science: the auditory brain, vol 2 (Rees A, Palmer AR, eds), pp 543-560. Oxford: Oxford UP.

Eggermont JJ, Kenmochi M (1998) Salicylate and quinine selectively enhance spontaneous firing rates in secondary auditory cortex. Hear Res 117:149-160.

Eggermont JJ, Komiya H (2000) Moderate noise trauma in juvenile cats results in profound cortical topographic map changes in adulthood. Hear Res 142:89-101.

Eggermont JJ, Roberts LE (2004) The neuroscience of tinnitus. Trends Neurosci 27:676-682.

Emmerich E, Richter F, Hagner H, Giessler F, Gehrlein S, Dieroff HG (2002) Effects of discotheque music on audiometric results and central acoustic evoked neuromagnetic responses. Int Tinnitus J 8:13-19.

Finlayson PG, Kaltenbach JA (2009) Alterations in the spontaneous discharge patterns of single units in the dorsal cochlear nucleus following intense sound exposure. Hear Res 256:104-117.

Foeller E, Vater M, Kössl M (2001) Laminar analysis of inhibition in the gerbil primary auditory cortex. J Assoc Res Otolaryngol 2:279-296.

Frisina RD (2010) Aging changes in the central auditory system. In: The Oxford handbook of auditory science: the auditory brain, vol 2 (Rees A, Palmer AR, eds), pp 418-438. Oxford: Oxford UP.

Giraud AL, Chéry-Croze S, Fischer G, Fischer C, Vighetto A, Grégoire MC, Lavenne F, Collet L (1999) A selective imaging of tinnitus. Neuroreport 10:1-5.

Gu J, Halpin C, Nam EC, Levine RA, Melcher JR (2008) Elevated soundevoked fMRI activation in the auditory midbrain of people with tinnitus and hyperacusis. Assoc Res Otolaryngol 31:336.

Gu JW, Halpin CF, Nam EC, Levine RA, Melcher JR (2010) Tinnitus, diminished sound-level tolerance, and elevated auditory activity in humans with normal hearing sensitivity. J Neurophysiol. Advance online publication. Retrieved September 29, 2010. doi:10.1152/jn00226.2010.

Hackney CM, Osen KK, Kolston J (1990) Anatomy of the cochlear nuclear complex of guinea pig. Anat Embryol (Berl) 182:123-149.

House JW, Brackmann DE (1981) Tinnitus: surgical treatment. Ciba Found Symp 85:204-216.

Hughes LF, Turner JG, Parrish JL, Caspary DM (2010) Processing of broadband stimuli across A1 layers in young and aged rats. Hear Res 264:79-85.

Jain R, Shore S (2006) External inferior colliculus integrates trigeminal and acoustic information: unit responses to trigeminal nucleus and acoustic stimulation in the guinea pig. Neurosci Lett 395:71-75.

Jastreboff PJ, Gray WC, Gold SL (1996) Neurophysiological approach to tinnitus patients. Am J Otol 17:236-240.

Job A, Raynal M, Kossowski M (2007) Susceptibility to tinnitus revealed at 2 $\mathrm{kHz}$ range by bilateral lower DPOAEs in normal hearing subjects with noise exposure. Audiol Neurootol 12:137-144.

Kaltenbach JA (2006) Summary of evidence pointing to a role of the dorsal cochlear nucleus in the etiology of tinnitus. Acta Otolaryngol Suppl 556:20-26.

Kaltenbach JA, Rachel JD, Mathog TA, Zhang J, Falzarano PR, Lewandowski M (2002) Cisplatin-induced hyperactivity in the dorsal cochlea nucleus and its relation to outer hair cell loss: relevance to tinnitus. J Neurophysiol 88:699-714.

Kaltenbach JA, Zacharek MA, Zhang J, Frederick S (2004) Activity in the dorsal cochlear nucleus of hamsters previously tested for tinnitus following intense tone exposure. Neurosci Lett 355:121-125.

Kaltenbach JA, Zhang J, Finlayson P (2005) Tinnitus as a plastic phenomenon and its possible neural underpinnings in dorsal cochlear nucleus. Hear Res 206:200-226.

Kanold PO, Young ED (2001) Proprioceptive information from the pinna 
provides somatosensory input to cat dorsal cochlear nucleus. J Neurosci 21:7848-7858.

Kiang NYS, Moxon FC, Levine RA (1969) Auditory nerve activity in cats with normal and abnormal cochleas. In: Ciba Foundation symposium on sensorineural hearing loss (Wolstenholme GEW, Knight J, eds), pp 241273. London: Churchill.

König O, Schaette R, Kempter R, Gross M (2006) Course of hearing loss and occurrence of tinnitus. Hear Res 221:59-64.

Kujawa SG, Liberman MC (2006) Acceleration of age-related hearing loss by early noise exposure: evidence of a misspent youth. J Neurosci 26:2115-2123.

Kujawa SG, Liberman MC (2009) Adding insult to injury: cochlear nerve degeneration after "temporary" noise-induced hearing loss. J Neurosci 29:14077-14085.

Landgrebe M, Langguth B, Rosengarth K, Braun S, Koch A, Kleinjung T, May A, de Ridder D, Hajak G (2009) Structural brain changes in tinnitus: grey matter decrease in auditory and non-auditory brain areas. Neuroimage 46:213-218.

Lanting CP, de Kleine E, van Dijk P (2009) Neural activity underlying tinnitus generation: results from PET and fMRI. Hear Res 255:1-13.

Levine RA (1999) Somatic (craniocervical) tinnitus and the dorsal cochlear nucleus hypothesis. Am J Otolaryngol 20:351-362.

Levine RA (2006) Typewriter tinnitus: a carbamazepine-responsive syndrome related to auditory nerve vascular compression. ORL J Otorhinolaryngol Relat Spec 68:43-47.

Lew HL, Jerger JF, Guillory SB, Henry JA (2007) Auditory dysfunction in traumatic brain injury. J Rehabil Res Dev 44:921-928.

Ling LL, Hughes LF, Caspary DM (2005) Aged-related loss of the GABA synthetic enzyme in rat primary auditory cortex. Neuroscience 132:1103-1113.

Llinás R, Urbano FJ, Leznik E, Ramírez RR, van Marle HJ (2005) Rhythmic and dysrhythmic thalamocortical dynamics: GABA systems and the edge effect. Trends Neurosci 28:325-333.

Lockwood AH, Salvi RJ, Coad ML, Towsley ML, Wack DS, Murphy BW (1998) The functional neuroanatomy of tinnitus: evidence for limbic system inks and neural plasticity. Neurology 50:114-120.

Ma WL, Hidaka H, May BJ (2006) Spontaneous activity in the inferior colliculus of $\mathrm{CBA} / \mathrm{J}$ mice after manipulations that induce tinnitus. Hear Res 212:9-21.

Masuda N, Kori H (2007) Formation of feedforward networks and frequency synchrony by spike-timing-dependent plasticity. J Comput Neurosci 22:327-345.

Melcher JR, Levine RA, Bergevin C, Norris B (2009) The auditory midbrain of people with tinnitus: abnormal sound-evoked activity revisited. Hear Res 257:63-74.

Mirz F, Gjedde A, Ishizu K, Pedersen CB (2000) Cortical networks subserving the perception of tinnitus-a PET study. Acta Otolaryngol Suppl 543:241-243.

Moffat G, Adjout K, Gallego S, Thai-Van H, Collet L, Noreña AJ (2009) Effects of hearing aid fitting on the perceptual characteristics of tinnitus. Hear Res 254:82-91.

Mühlau M, Rauschecker JP, Oestreicher E, Gaser C, Röttinger M, Wohlschläger AM, Simon F, Etgen T, Conrad B, Sander D (2006) Structural brain changes in tinnitus. Cereb Cortex 16:1283-1288.

Mulders WH, Robertson D (2009) Hyperactivity in the auditory midbrain after acoustic trauma: dependence on cochlear activity. Neuroscience 164:733-746.

Niskar AS, Kieszak SM, Holmes AE, Esteban E, Rubin C, Brody DJ (2001) Estimated prevalence of noise-induced hearing threshold shifts among children 6 to 19 years of age: the Third National Health and Nutrition Examination Survey, 1988-1994, United States. Pediatrics 108:40-43.

Noreña A, Micheyl C, Chéry-Croze S, Collet L (2002) Psychoacoustic characterization of the tinnitus spectrum: Implications for the underlying mechanisms of tinnitus. Audiol Neurootol 7:358-369.

Noreña AJ, Chery-Croze S (2007) Enriched acoustic environment rescales auditory sensitivity. Neuroreport 18:1251-1255.

Noreña AJ, Eggermont JJ (2003) Changes in spontaneous neural activity immediately after an acoustic trauma: implications for neural correlates of tinnitus. Hear Res 183:137-153.

Noreña AJ, Eggermont JJ (2005) Enriched acoustic environment after noise trauma reduces hearing loss and prevents cortical map reorganization. J Neurosci 25:699-705.
Noreña AJ, Eggermont JJ (2006) Enriched acoustic environment after noise trauma abolishes neural signs of tinnitus. Neuroreport 17:559-563.

Pinchoff RJ, Burkard RF, Salvi RJ, Coad ML, Lockwood AH (1998) Modulation of tinnitus by voluntary jaw movements. Am J Otol 19:785-789.

Plewnia C, Reimold M, Najib A, Brehm B, Reischl G, Plontke SK, Gerloff C (2007) Dose-dependent attenuation of auditory phantom perception (tinnitus) by PET-guided repetitive transcranial magnetic stimulation. Hum Brain Mapp 28:238-246.

Popelár J, Syka J, Berndt H (1987) Effect of noise on auditory evoked responses in awake guinea pigs. Hear Res 26:239-247.

Prieto JJ, Peterson BA, Winer JA (1994a) Morphology and spatial distribution of GABAergic neurons in cat primary auditory cortex (AI). J Comp Neurol 344:349-382.

Prieto JJ, Peterson BA, Winer JA (1994b) Laminar distribution and neuronal targets of GABAergic axon terminals in cat primary auditory cortex (AI). J Comp Neurol 344:383-402.

Rachel JD, Kaltenbach JA, Janisse J (2002) Increases in spontaneous neural activity in the hamster dorsal cochlear nucleus following cisplatin treatment: a possible basis for cisplatin-induced tinnitus. Hear Res 164:206214.

Rajan R, Irvine DR (1998) Neuronal responses across cortical field A1 in plasticity induced by peripheral auditory organ damage. Audiol Neurootol 3:123-144.

Rauschecker JP, Leaver AM, Mühlau M (2010) Tuning out the noise: limbic-auditory interactions in tinnitus. Neuron 66:819-826.

Roberts LE, Moffat G, Baumann M, Ward LM, Bosnyak DJ (2008) Residual inhibition functions overlap tinnitus spectra and the region of auditory threshold shift. J Assoc Res Otolaryngol 9:417-435.

Rubinstein B, Axelsson A, Carlsson GE (1990) Prevalence of signs and symptoms of craniomandibular disorders in tinnitus patients J Craniomandib Disord 4:186-192.

Salvi RJ, Wang J, Ding D (2000) Auditory plasticity and hyperactivity following cochlear damage. Hear Res 147:261-274.

Schaette R, Kempter R (2006) Development of tinnitus-related neuronal hyperactivity through homeostatic plasticity after hearing loss: a computational model. Eur J Neurosci 23:3124-3138.

Schlee W, Weisz N, Bertrand O, Hartmann T, Elbert T (2008) Using auditory steady-state responses to outline the functional connectivity in the tinnitus brain. PLoS One 3:e3720.

Schneider P, Andermann M, Wengenroth M, Goebel R, Flor H, Rupp A, Diesch E (2009) Reduced volume of Heschl's gyrus in tinnitus. Neuroimage 45:927-939.

Seki S, Eggermont JJ (2003) Changes in spontaneous firing rate and neural synchrony in cat primary auditory cortex after localized tone-induced hearing loss. Hear Res 180:28-38.

Shore S, Zhou J, Koehler S (2007) Neural mechanisms underlying somatic tinnitus. Prog Brain Res 166C:107-548.

Shore SE (2005) Sensory nuclei in tinnitus. In: Tinnitus: theory and management (Snow JB, ed), pp 125-141. Hamilton, ON, Canada: Decker.

Shore SE, El Kashlan H, Lu J (2003) Effects of trigeminal ganglion stimulation on unit activity of ventral cochlear nucleus neurons. Neuroscience 119:1085-1101.

Shore SE, Koehler S, Oldakowski M, Hughes LF, Syed S (2008) Dorsal cochlear nucleus responses to somatosensory stimulation are enhanced after noise-induced hearing loss. Eur J Neurosci 27:155-168.

Singer W (1999) Neuronal synchrony: a versatile code for the definition of relations? Neuron 24:49-65.

Syka J (2002) Plastic changes in the central auditory system after hearing loss, restoration of function, and during learning. Physiol Rev 82:601-636.

Syka J, Rybalko N, Popelár J (1994) Enhancement of the auditory cortex evoked responses in awake guinea pigs after noise exposure. Hear Res 78:158-168.

Takahashi YK, Kori H, Masuda N (2009) Self-organization of feed-forward structure and entrainment in excitatory neural networks with spiketiming-dependent plasticity. Phys Rev E Stat Nonlin Soft Matter Phys 79:051904.

Terry AM, Jones DM, Davis BR, Slater R (1983) Parametric studies of tinnitus masking and residual inhibition. Br J Audiol 17:245-256.

Turner JG, Hughes LF, Caspary DM (2005) Effects of aging on receptive fields in rat primary auditory cortex layer V neurons. J Neurophysiol 94:2738-2747. 
Turrigiano GG, Nelson SB (2004) Homeostatic plasticity in the developing nervous system. Nat Rev Neurosci 5:97-107.

Tzounopoulos T, Rubio ME, Keen JE, Trussell LO (2007) Coactivation of pre- and postsynaptic signaling mechanisms determines cell-specific spike-timing-dependent plasticity. Neuron 54:291-301.

Vernon JA, Meikle MB (2003) Tinnitus: clinical measurement. Otolaryngol Clin North Am 36:293-305.

Wang H, Turner JG, Ling L, Parrish JL, Hughes LF, Caspary DM (2009a) Age-related changes in glycine receptor subunit composition and binding in dorsal cochlear nucleus. Neuroscience 160:227-239.

Wang H, Brozoski TJ, Turner JG, Ling L, Parrish JL, Hughes LF, Caspary DM (2009b) Plasticity at glycinergic synapses in dorsal cochlear nucleus of rats with behavioral evidence of tinnitus. Neuroscience 164:747-759.

Wang J, McFadden SL, Caspary D, Salvi R (2002) Gamma-aminobutyric acid circuits shape response properties of auditory cortex neurons. Brain Res 944:219-231.

Weisz N, Hartmann T, Dohrmann K, Schlee W, Noreña A (2006) Highfrequency tinnitus without hearing loss does not mean absence of deafferentation. Hear Res 222:108-114.
Weisz N, Müller S, Schlee W, Dohrmann K, Hartmann T, Elbert T (2007) The neural code of auditory phantom perception. J Neurosci 27:1479-1484

Wienbruch C, Paul I, Weisz N, Elbert T, Roberts LE (2006) Frequency organization of the $40-\mathrm{Hz}$ auditory steady-state response in normal hearing and in tinnitus. Neuroimage 33:180-194.

Willott JF, Aitkin LM, McFadden SL (1993) Plasticity of auditory cortex associated with sensorineural hearing loss in adult C57BL/6J mice. J Comp Neurol 329:402-411.

Zacharek MA, Kaltenbach JA, Mathog TA, Zhang J (2002) Effects of cochlear ablation on noise induced hyperactivity in the hamster dorsal cochlear nucleus: implications for the origin of noise induced tinnitus. Hear Res 172:137-143.

Zeng C, Nannapaneni N, Zhou J, Hughes LF, Shore S (2009) Cochlear damage changes the distribution of vesicular glutamate transporters associated with auditory and nonauditory inputs to the cochlear nucleus. J Neurosci 29:4210-4217.

Zhou J, Shore S (2006) Convergence of spinal trigeminal and cochlear nucleus projections in the inferior colliculus of the guinea pig. J Comp Neurol 495:100-112. 